\title{
Application of CEEMD noise reduction algorithm in ultrasound imaging in evaluating fetuses with abnormal glucose metabolism in late pregnancy
}

\author{
Junfeng Huang ${ }^{1}$, Cuiting Wang ${ }^{2}$, \\ Xianxia $\mathrm{Li}^{3}$, Yuqin Jing ${ }^{4}$
}

\begin{abstract}
Objectives: To explore the predictive effect of abnormal glucose metabolism and fetal hemodynamic parameters on adverse pregnancy outcome

Methods: One hundred and nine pregnant women with abnormal glucose metabolism during pregnancy from June 2016 to October 2018 were selected and divided into poor prognosis group (34 cases) and good prognosis group (75 cases). The hemodynamic parameters of fetal cerebral artery (MCA), umbilical artery (UA) and uterine artery of pregnancy (UT-A), including peak systolic velocity (S / D), resistance index (RI) and plasticity index (PI), were measured by color Doppler ultrasound. The receiver operating characteristic (ROC) curve of adverse pregnancy outcomes was drawn and the best threshold index was determined.

Results: MCA-PI poor prognosis group, MCA-RI, RI ratio (MCA/UA) are lower than the good prognosis group, Ut-A-PI is higher than the good prognosis group $(P<0.05$,$) . ROC curve analysis results show that when the$ MCA-PI 1.56, the sensitivity of the predicted adverse outcomes of pregnancy, the highest specificity<, was $91.18 \%, 80.00 \%$, respectively. Logistic regression analysis of risk factors shows poor pregnancy outcomes include: pregnant women, older age, body mass index $\geq 24.0 \mathrm{~kg} / \mathrm{m} 2$ and a family history of diabetes. Protective factors include exercise during pregnancy, MCA-PI $\geq 1.56, M C A-R I \geq 0.63$ and $\mathrm{RI}$ The ratio (MCA/ $\mathrm{UA}) \geq 0.84$.

Conclusion: Color Doppler ultrasound measured MCA-PI $<1.56$ the most important indicators of poor pregnancy outcomes as abnormal glucose metabolism during pregnancy and predict the exact cutoff. Pregnant women, older age, body mass index $\geq 24.0 \mathrm{~kg} / \mathrm{m} 2$ and a family history of diabetes and abnormal glucose metabolism during pregnancy risk factors for adverse outcomes of pregnancy.
\end{abstract}

KEYWORDS: Glucose metabolism; Late pregnancy; Receiver operating characteristic; Measured fetal brain artery; Umbilical artery.

doi: https://doi.org/10.12669/pjms.37.6-WIT.4844

How to cite this:

Huang J, Wang C, Li X, Jing Y. Application of CEEMD noise reduction algorithm in ultrasound imaging in evaluating fetuses with abnormal glucose metabolism in late pregnancy. Pak J Med Sci. 2021;37(6):1590-1594.

doi: https://doi.org/10.12669/pjms.37.6-WIT.4844

This is an Open Access article distributed under the terms of the Creative Commons Attribution License (http://creativecommons.org/licenses/by/3.0), which permits unrestricted use, distribution, and reproduction in any medium, provided the original work is properly cited.

Correspondence:

Yuqin Jing,

Department of Surgical,

Maternal and Child Health Hospital of Jinan City, Jinan 250001,

Shandong, China.

E-mail: jingyuqinmchh@126.com

* Received for Publication:

* Revision Received:

* Second Revision Received:

* Final Revision Accepted:
April 13, 2021

June 9,2021

June 14, 2021

July 8, 2021

\section{INTRODUCTION}

Abnormal glucose metabolism during pregnancy includes diabetes with pregnancy and gestational diabetes. Its incidence has increased in recent years, which is a common complication during pregnancy, resulting in 4 times the perinatal morbidity and mortality compared to normal pregnancy. Abnormal glucose metabolism during pregnancy can reduce the placenta's blood supply to the fetus, and the fetus is in a state of high blood sugar and 
high insulin, which will cause the body to consume more oxygen, cause fetal hypoxia, and restrict growth,. and fetal health. Because ultrasound can dynamically monitor the fetal blood circulation in the uterus, the study of fetal hemodynamics by ultrasound has become very popular in recent years. ${ }^{1-3}$ This study used color Doppler ultrasound to measure the hemodynamic parameters of pregnant women with abnormal glucose metabolism during pregnancy and their fetuses, to determine the most important indicators and cutoffs for predicting adverse pregnancy outcomes. Our objective was to study factors affecting adverse pregnancy outcomes to prevent their occurrence.

\section{METHODS}

A total of 109 pregnant women with abnormal glucose metabolism during pregnancy who were treated in our hospital from June 2016 to October 2018 were selected. There were 34 cases with good prognosis. The pregnant women were 20-42 years old, with an average of $(27.68 \pm 3.93)$ years old. Mean gestational age was 38 check +6 week's gestation. Delivery methods are supposed to ensure smooth process and safe delivery.
Any one or more of the following is considered to be a poor pregnancy outcome: 1 . newborn body weight >90th percentile of the same gestational week; 2 . primary cesarean section; 3. clinical neonatal hypoglycemia; 4. neonatal hyperinsulinemia; 5 . premature delivery; 6 . neonatal hyperbilirubinemia; 7. fetal distress; 8. neonatal asphyxia; 9. amniotic fluid turbidity above II degree or oligohydramnios. ${ }^{4,5}$

Philips iU 22 using color Doppler ultrasound, C5-2 abdominal probe, the frequency of $3.0-5.0 \mathrm{MHz}$ Checking pregnant holding supine position, fully exposed to the abdomen, were measured by color Doppler ultrasound fetal brain artery (the MCA), hemodynamic parameters umbilical artery (UA) and pregnant uterine artery (Ut-A), comprising: late peak systolic velocity/systolic blood flow velocity $(\mathrm{S} / \mathrm{D})$, the resistance index (RI) and pulsatility index (PI). 1. UA: Use two-dimensional ultrasound to locate the free umbilical cord, and choose the sampling point as the filling point of blood flow signal. 2. MCA: Use two-dimensional ultrasound to find the fetal head. When the fetal biparietal standard measurement section is displayed, move the probe parallel to the skull base direction. Use

Table-I: Comparison of hemodynamic parameters of pregnant women and fetuses between two groups ( $\mathrm{x} \pm \mathrm{s})$.

\begin{tabular}{|c|c|c|c|c|c|c|c|c|c|}
\hline \multirow{2}{*}{ Group } & \multicolumn{3}{|c|}{$M C A$} & \multicolumn{3}{|c|}{$U A$} & \multicolumn{3}{|c|}{$U t-A$} \\
\hline & PI & $R I$ & $S / D$ & PI & $R I$ & $S / D$ & PI & $R I$ & $S / D$ \\
\hline Poor & $\begin{array}{c}1.51 \pm \\
0.12\end{array}$ & $\begin{array}{c}0.53 \pm \\
0.10\end{array}$ & $\begin{array}{c}3.30 \pm \\
0.77\end{array}$ & $\begin{array}{c}1.21 \pm \\
0.25\end{array}$ & $\begin{array}{c}0.74 \pm \\
0.12\end{array}$ & $\begin{array}{c}3.67 \pm \\
0.94\end{array}$ & $\begin{array}{c}0.84 \pm \\
0.12\end{array}$ & $\begin{array}{c}0.61 \pm \\
0.08\end{array}$ & $\begin{array}{c}2.28 \pm \\
0.20\end{array}$ \\
\hline Good & $\begin{array}{c}1.61 \pm \\
0.11\end{array}$ & $\begin{array}{c}0.63 \pm \\
0.09\end{array}$ & $\begin{array}{c}3.34 \pm \\
0.48\end{array}$ & $\begin{array}{c}1.17 \pm \\
0.13\end{array}$ & $\begin{array}{c}0.71 \pm \\
0.12\end{array}$ & $\begin{array}{c}3.51 \pm \\
1.11\end{array}$ & $\begin{array}{c}0.76 \pm \\
0.13\end{array}$ & $\begin{array}{c}0.58 \pm \\
0.07\end{array}$ & $\begin{array}{c}2.24 \pm \\
0.21\end{array}$ \\
\hline$t$ & 3.788 & 4.958 & 0.661 & 0.981 & 1.18 & 1.387 & 3.192 & 1.498 & 0.868 \\
\hline $\mathrm{P}$ & 0 & 0 & 0.509 & 0.329 & 0.241 & 0.166 & 0.002 & 0.137 & 0.868 \\
\hline \multirow{2}{*}{ Group } & PI ratio & RI ratio & $\begin{array}{l}S / D \\
\text { ratio }\end{array}$ & PI ratio & RI ratio & $\begin{array}{l}S / D \\
\text { ratio }\end{array}$ & PI ratio & RI ratio & $\begin{array}{l}S / D \\
\text { ratio }\end{array}$ \\
\hline & $\begin{array}{c}(M C A / \\
U A)\end{array}$ & $\begin{array}{c}(M C A / \\
U A)\end{array}$ & $\begin{array}{c}(M C A / \\
U A)\end{array}$ & $\begin{array}{c}(M C A / \\
U A)\end{array}$ & $\begin{array}{c}(M C A / \\
U A)\end{array}$ & $\begin{array}{c}(M C A) \\
U A)\end{array}$ & $\begin{array}{c}(M C A) \\
U A)\end{array}$ & $\begin{array}{c}(M C A) \\
U A)\end{array}$ & $\begin{array}{c}(M C A) \\
U A)\end{array}$ \\
\hline Poor & $\begin{array}{c}1.30 \pm \\
0.27\end{array}$ & $\begin{array}{c}0.72 \pm \\
0.13\end{array}$ & $\begin{array}{c}0.94 \pm \\
0.26\end{array}$ & $\begin{array}{c}0.84 \pm \\
0.30\end{array}$ & $\begin{array}{c}1.02 \pm \\
0.26\end{array}$ & $\begin{array}{c}0.77 \pm \\
0.22\end{array}$ & $\begin{array}{c}0.68 \pm \\
0.12\end{array}$ & $\begin{array}{c}0.75 \pm \\
0.12\end{array}$ & $\begin{array}{c}0.84 \pm \\
0.24\end{array}$ \\
\hline Good & $\begin{array}{c}1.39 \pm \\
0.18\end{array}$ & $\begin{array}{c}0.90 \pm \\
0.15\end{array}$ & $\begin{array}{c}1.01 \pm \\
0.25\end{array}$ & $\begin{array}{c}0.91 \pm \\
0.23\end{array}$ & $\begin{array}{c}0.98 \pm \\
0.27\end{array}$ & $\begin{array}{c}0.76 \pm \\
0.28\end{array}$ & $\begin{array}{c}0.67 \pm \\
0.14\end{array}$ & $\begin{array}{c}0.74 \pm \\
0.12\end{array}$ & $\begin{array}{c}0.85 \pm \\
0.27\end{array}$ \\
\hline $\mathrm{t}$ & 1.582 & 6.418 & 0.108 & 0.121 & 1.312 & 1.221 & 1.449 & 1.453 & 1.691 \\
\hline P & 0.117 & 0 & 0.198 & 0.167 & 0.15 & 0.159 & 0.142 & 0.156 & 0.103 \\
\hline
\end{tabular}

MCA: middle cerebral artery; UA: umbilical artery; Ut-A: uterine artery; PI: plasticity index;

RI: resistance index; S/D: peak systolic flow rate/end-systolic blood flow velocity. 
Table-II: Predictive effects of various hemodynamic parameters on adverse pregnancy outcomes during abnormal glucose metabolism during pregnancy.

\begin{tabular}{lccccccc}
\hline $\begin{array}{l}\text { Hemodynamic } \\
\text { parameters }\end{array}$ & $\begin{array}{c}\text { Area under } \\
\text { the curve }\end{array}$ & $95 \%$ & $P$ & Critical & $\begin{array}{c}\text { Sensitivity } \\
(\%)\end{array}$ & $\begin{array}{c}\text { Specificity } \\
(\%)\end{array}$ & $\begin{array}{c}\text { Yoden } \\
\text { index }\end{array}$ \\
\hline MCA-PI & 0.8 & $0.702 \sim 0.899$ & 0 & $<1.56$ & 91.18 & 80 & 0.712 \\
MCA-RI & 0.767 & $0.668 \sim 0.865$ & 0 & $<0.63$ & 47.06 & 96 & 0.431 \\
Ut-A-PI & 0.704 & $0.590 \sim 0.817$ & 0.001 & $\geq 0.72$ & 44.12 & 85.33 & 0.295 \\
RI ratio (MCA/UA) & 0.832 & $0.749 \sim 0.915$ & 0 & $<0.84$ & 67.65 & 92 & 0.596 \\
\hline
\end{tabular}

MCA: cerebral arteries; Ut-A: uterine arteries; UA: umbilical arteries; PI: pulse index; RI: resistance index.

color Doppler ultrasound to clearly display the fetal middle cerebral artery when sampling. point. 3. UtA: Look up the internal iliac artery from the groin on both sides of the pregnant woman and find the main uterine artery from the distal branch of the internal iliac artery. During the measurement, adjust the color Doppler sampling volume to $2 \mathrm{~mm}$, keep the angle between the pulse sampling line and the blood vessel at $0-30^{\circ}$, freeze the image when more than five continuous stable standard waveforms are obtained, and take the average of three consecutive measurements. The signal sampling time does not exceed one minute.

\section{RESULTS}

Comparison of hemodynamic parameters of pregnant women and fetuses between two groups Poor prognosis group MCA-PI, MCA-RI and RI ratio (MCA/UA) are lower than the good prognosis group, Ut-A-PI is higher than the good prognosis group, the differences were statistically significant $(\mathrm{P}<0.05)$; the remaining each parameter difference was not statistically significant. Table-I. ${ }^{6}$

Analysis of ROC curve: With MCA-PI $<1.56$ as the cut-off value, the sensitivity and specificity of predicting adverse pregnancy outcomes of abnormal glucose metabolism during pregnancy are high, $91.18 \%$ and $80.00 \%$, respectively, and the area under the curve is 0.800 , Table-II and Fig.1.
Univariate analysis: Related characteristics were compared, results showed that: two groups were statistically significant (all $\mathrm{P}<0.05$ ) in age, highdensity lipoprotein, body mass index, family history of diabetes during pregnancy and whether the movement, the difference. Table-III.

\section{DISCUSSION}

In this study, the hemodynamic parameters of fetal middle cerebral artery of some pregnant women with abnormal glucose metabolism during pregnancy changed compared with those of normal pregnant women. The blood flow resistance index PI, RI, S/D was lower than that of normal pregnant women, but no adverse outcome occurred.7-10

Results of this study MCA-PI poor prognosis group, MCARI, RI ratio (MCA/UA) are lower than the good prognosis group, Ut-A-PI poor prognosis group than good prognosis group, the differences were statistically significant (all $\mathrm{P}<0.05$ ), in line with cerebral protection effect, consistent with the findings. When MCA-PI $<1.56$ is taken as the critical value, the sensitivity and specificity were $91.18 \%$, $80.00 \%$, area under the curve 0.800 , consistent with previous studies. ${ }^{11-13}$

Studies by Jugovic et al. Showed that the decrease in RI ratio (MCA/UA) was related to intrauterine hypoxia. Fetal babies with RI ratio (MCA/UA) $<1$ were five minutes after birth, Apgar score, umbilical

Table-III: Comparison of two groups of general information.

\begin{tabular}{|c|c|c|c|c|c|c|c|c|}
\hline \multirow[t]{2}{*}{ Group } & \multicolumn{2}{|c|}{$\begin{array}{l}\text { Family history of } \\
\text { diabetes (example) }\end{array}$} & \multicolumn{2}{|c|}{$\begin{array}{c}\text { Family history of } \\
\text { hypertension (example) }\end{array}$} & \multicolumn{2}{|c|}{$\begin{array}{c}\text { Exercise during } \\
\text { pregnancy (example) }\end{array}$} & \multicolumn{2}{|c|}{$\begin{array}{l}\text { Body mass index } \\
(\mathrm{kg} / \mathrm{m} 2)\end{array}$} \\
\hline & no & Have & no & Have & no & Have & $\leq 23.9$ & $\geq 24.0$ \\
\hline Poor prognosis group (75) & 49 & 26 & 52 & 23 & 52 & 23 & 34 & 41 \\
\hline Good prognosis group (34) & 32 & 2 & 23 & 11 & 11 & 23 & 27 & 7 \\
\hline$X^{2} / t / Z$ & \multicolumn{2}{|c|}{10.154} & \multicolumn{2}{|c|}{0.031} & \multicolumn{2}{|c|}{13.116} & \multicolumn{2}{|c|}{11.024} \\
\hline $\mathrm{P}$ & \multicolumn{2}{|c|}{0.001} & \multicolumn{2}{|c|}{0.86} & \multicolumn{2}{|c|}{0.001} & \multicolumn{2}{|c|}{0.001} \\
\hline
\end{tabular}




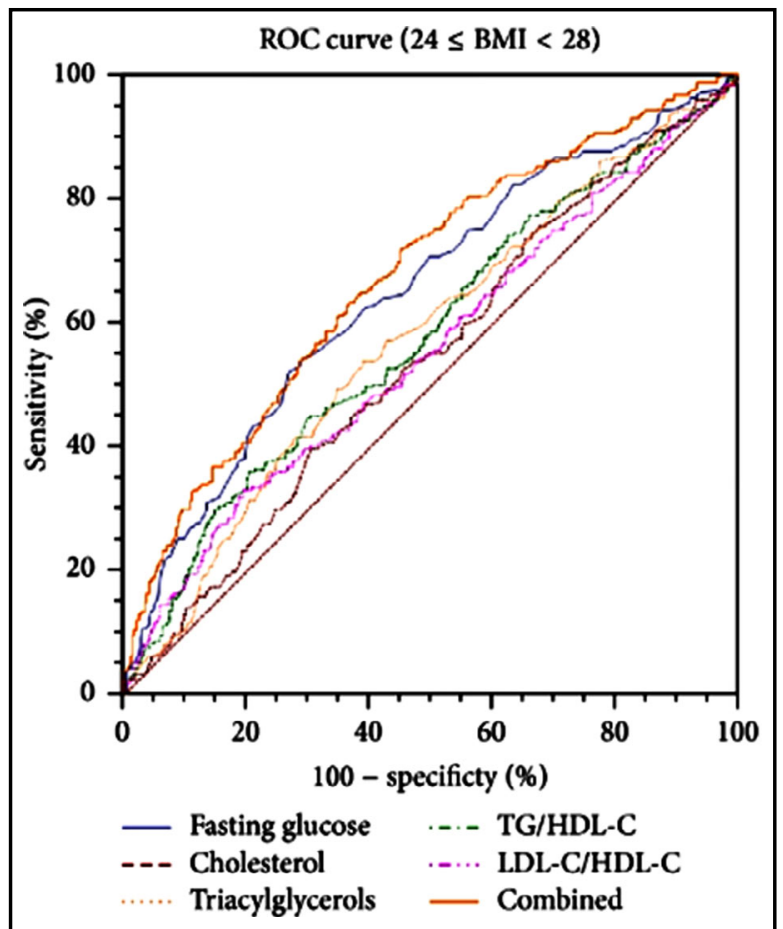

Fig.1: ROC curve of various parameters predicting adverse pregnancy outcomes due to abnormal glucose metabolism during pregnancy.

artery blood gas acid-base status, and oxygen. Fetal partial pressures are significantly lower than those of fetuses with RI ratio (MCA/UA) $>1$, which was similar to the results of this work ${ }^{14-15}$. In addition, studies proved that the umbilical artery has a certain application value in the evaluation of fetal hypoxia. When fetal hypoxia occurs, the blood flow of the umbilical artery decreases significantly and the blood flow resistance index increases significantly ${ }^{16-18}$. The results of this study are consistent with those of the above investigators.

Studies have suggested that pregnant women with a family history of diabetes have a five times higher risk of abnormal pregnancy outcomes than pregnant women without a family history of diabetes ${ }^{19}$. In addition, prolonged maternal hyperglycemia causes abnormal hyperplasia of fetal islet B cells and adipocytes, leading to obesity and abnormal glucose metabolism in neonates, which result in adverse pregnancy outcomes. ${ }^{20}$

Exercise during pregnancy, MCA-PI $\geq 1.56$, MCA-RI $\geq 0.63$, and RI ratio (MCA/UA) $\geq 0.84$ are protective factors for pregnancy prognosis. At present, the index of S/D of umbilical artery is still widely used in clinic, and the S/D $>3$ of fetal umbilical blood flow in late pregnancy indicates the possibility of fetal intrauterine hypoxia, but the results are not satisfactory. Therefore, it is still an important task to improve the accuracy of predicting the adverse pregnancy outcomes of abnormal glucose metabolism during pregnancy. Accurate prediction of adverse pregnancy outcomes due to abnormal glucose metabolism during pregnancy can not only reduce adverse pregnancy outcomes such as neonatal encephalopathy, neonatal asphyxia and neonatal death, but also reduce unnecessary cesarean deliveries due to clinical prediction errors. In this study, ROC curve analysis of different hemodynamic parameters and adverse pregnancy outcomes showed that in a single hemodynamic parameter, MCA-PI, MCA-RI, and UT-A-RI can all be used as indicators to predict adverse pregnancy outcomes. However, among the combined parameters, only RI ratio (UA/MCA) could be used as a predictor of adverse pregnancy outcomes. The ROC curve analysis in this study showed that the accuracy of combined hemodynamic parameter RI ratio (UA/ MCA) was better than that of single hemodynamic parameter MCA-PI. When MCA-PI $\geq 1.56$, MCA$\mathrm{RI} \geq 0.63$, and RI ratio (MCA/UA) $\geq 0.84$, the fetal blood circulation in the mother's body conforms to the physiological state of the fetal stage. Currently, MCA hemodynamics is in a high-impedance state, and peripheral blood vessels UA and Ut-A are in a low-resistance state. When they are abnormal, the fetus appears hypoxic, which causes poor pregnancy outcomes such as amniotic fluid pollution.

Limitations of the study: Due to the time, morbidity, and the fact that the hospital is not a specialist obstetrics and gynecology hospital, the sample size is limited and the number of cases in the pregestational diabetes group is small, which results in a certain degree of deviation in the research results. Therefore, the researchers will continue to collect as many cases as possible in the future work for further in-depth study.

\section{CONCLUSIONS}

Color Doppler ultrasound can be used to obtain hemodynamic parameters to predict adverse pregnancy outcomes in pregnant women with abnormal glucose metabolism during pregnancy, assess fetal intrauterine conditions, and provide clinical ultrasound to predict adverse pregnancy outcomes in patients with abnormal glucose metabolism during pregnancy. Quantitative indicators; comprehensive evaluation of the influencing factors of abnormal glucose metabolism during pregnancy will help early detection of intrauterine abnormalities in the fetus and prevent adverse pregnancy outcomes. 


\section{REFERENCES}

1. Jou MY, Philipps AF, Lonnerdal B. Maternal zinc deficiency in rats affects growth and glucose metabolism in the offspring by inducing insulin resistance postnatally. J Nutr. 2010;140(9):1621-1627. doi: 10.3945/jn.109.119677

2. O'Reilly MA, Jones RM, Hough O. Acoustically controlled ultrasound-mediated drug delivery to the central nervous system. J Acoustical Society of Aerica. 2016;139(4):2116 2116. doi: $10.1121 / 1.4950297$

3. Liang $\mathrm{W}$, Zhao YJ, Yang H. Effects of antioxidant system on coronary artery lesions in patients with abnormal glucose metabolism. Aging Clin Exp Res. 2017;29(2):141146. doi: $10.1007 /$ s40520-016-0564-z

4. Lai $Y$, Sun C, Association of abnormal glucose metabolism and insulin resistance in patients with atypical and typical endometrial cancer. Oncol Lett. 2018;15(2):2173-2178. doi: 10.3892/ol.2017.7590

5. Mokta J, Kumar S, Ganju N. High incidence of abnormal glucose metabolism in acute coronary syndrome patients at a moderate altitude: A sub-Himalayan study. Indian J Endocrinol Metab. 2017;21(1):142-147. doi: 10.4103/22308210.196019

6. Salomon C, Scholz-Romero K, Sarker S, Sweeney E, Kobayashi M, et al. Gestational Diabetes Mellitus Is Associated With Changes in the Concentration and Bioactivity of Placenta-Derived Exosomes in Maternal Circulation Across Gestation. Diabetes. 2016;65(3):598-609. doi: $10.2337 /$ db15-0966

7. Tomazic M, Janez A, Ravnik Oblak M. Hypoglycemia identified by a continuous glucose monitoring system in a second-trimester pregnant woman with insulinoma: A case report. J Med Case Rep. 2017;11(1):117. doi: 10.1186/ s13256-017-1265-8

8. Xiao Y, Zhang X. Association between maternal glucose/ lipid metabolism parameters and abnormal newborn birth weight in gestational diabetes complicated by preeclampsia: A Retrospective Analysis of 248 Cases. Diabetes Ther. 2020;11(4):905-914. doi: 10.1007/s13300020-00792-3

9. Damm P, Mersebach H, Rastam J, Kaaja R, Hod M, McCance DR, et al. Poor pregnancy outcome in women with type 1 diabetes is predicted by elevated HbA1c and spikes of high glucose values in the third trimester. J Matern Fetal Neonatal Med. 2014;27(2):149-154 doi: 10.3109/14767058.2013.806896

10. Kortekaas JC, Bruinsma A, Keulen JKJ. Management of late-term pregnancy in midwifery- and obstetrician-led care. BMC Pregnancy Childbirth. 2019;19(1):181. doi: 10.1186/s12884-019-2294-7

11. Sapra, K.J., Joseph, K.S., Galea, S., Bates, L.M., Louis, G.M., Ananth cvsigns and symptoms of early pregnancy loss. Reprod Sci. 2017;24(4):502-513. doi: $10.1177 / 1933719116654994$

12. Wessberg, A., Lundgren, I., Elden, H., Late-term pregnancy: navigating in unknown waters - a hermeneutic study. Women Birth. 2020;33(3):265-272. doi: 10.1016/j. wombi.2019.03.011.

13. Kortekaas JC, Kazemier BM, Keulen JKJ, Bruinsma A, Mol BW, Vandenbussche F, et al. Risk of adverse pregnancy outcomes of late- and postterm pregnancies in advanced maternal age: a national cohort study. Acta Obstet Gynecol Scand. 2020;99(8):1022-1030. doi: 10.1111/aogs.13828
14. Parildar H, Cigerli O, Unal AD, Gulmez O, Demirag NG. The impact of vitamin $\mathrm{d}$ replacement on glucose metabolism. Pak J Med Sci, 2013;29(6);1311-1314. doi: 10.12669 / pjms.296.3891

15. Silversides CK, Grewal J, Mason J, Sermer M, Kiess M. Pregnancy outcomes in women with heart disease: the carpreg ii study. J Am Coll Cardiol. 2018;71(21):2419-2430. doi: 10.1016/j.jacc.2018.02.076

16. Azzaroli F, Mazzella G, Marchesini G, Brodosi L, Petroni ML. Fatty liver in pregnancy: a narrative review of two distinct conditions. Expert Rev Gastroenterol Hepatol. 2020;14(2):127-135. doi: 10.1080/17474124.2020.1715210

17. Khalid N, Ahmad F, Qureshi FM, Association amid the comorbidity of diabetes mellitus in patients of active tuberculosis in pakistan: a matched case control study. Pak J Med Sci. 2021;37(3):816-820. doi: 10.12669/ pjms.37.3.3274

18. Kalkan IH, Suher M. The relationship between the level of glutathione, impairment of glucose metabolism and complications of diabetes mellitus. Pak J Med Sci, 2013;29(4), 938-942. doi: 10.12669/pjms.294.2859

19. Spong CY, Mercer BM, D'Alton M, Kilpatrick S, Blackwell $S$, Saade G. Timing of indicated late-preterm and earlyterm birth. Obstet Gynecol. 2011;118(2 Pt 1):323-333. doi: 10.1097/AOG.0b013e3182255999

20. Rosales Nieto CA, Mantey A, Makela B, Byrem T, Ehrhardt $\mathrm{R}$, Veiga-Lopez A. Shearing during late pregnancy increases size at birth but does not alter placental endocrine responses in sheep. Animal. 2020;14(4):799-806. doi: 10.1017/S1751731119002696

\section{Authors' Contribution:}

JH: Conceived the study, literature review, data analysis, drafting the manuscript.

CW \& XL: Helped in design, data collection, drafting the manuscript \& critical revision.

YJ: takes the responsibility and is accountable for all aspects of the work in ensuring that questions related to the accuracy or integrity of any part of the work are appropriately investigated and resolved.
Authors:

1. Junfeng Huang, Deputy Chief Nurse. Department of Nursing,

2. Cuiting Wang, Bachelor's Degrees. Department of Obstetrical,

3. Xianxia Li,

Supervisor nurse.

Department of Obstetrical,

4. Yuqin Jing,

Supervisor nurse.

Department of Surgical,

1-4: Maternal and Child Health Hospital of Jinan City, Jinan City 250001, Shandong Province, China. 